\title{
Introducción al trabajo de la Dra. Myriam Tarragó de Font
}

R. P. Gustavo Le Paige s. j. ${ }^{1}$

\begin{abstract}
¿Cómo agradecer a la Dra. Myriam Tarragó de Font por su estudio tan completo y detallado? Desgraciadamente este importante aporte científico estaba ya casi listo en el tiempo del Congreso de Americanistas en Mar del Plata (1966) y permanecía inédito hasta ahora. Entonces, mucho tiempo ha pasado, como bien lo reconoce su autora. Sin embargo, a pesar del tiempo, no han cambiado sus conclusiones, pues no hay novedades al respecto. A pesar de esto, es muy difícil en la región de San Pedro de Atacama considerar que no se incrementa este tipo de información. "Desgraciadamente" siempre hay nuevos datos que complementan estas investigaciones. Ahora contamos con referencias obtenidas de Coyo Oriental, Toconao, Sequitor Oriental (nuevos descubrimientos), Sequitor Occidental, Tulor, Coyo Occidental, Tchapuchayna, estos tres últimos con cerámica que llamamos "primitiva", anterior al tipo San Pedro Rojo Pulido. Estos nuevos datos se han descrito en el VI Congreso de Arqueología Chilena ("Tres cementerios indígenas en San Pedro de Atacama y Toconao") y en la revista Estudios Atacameños $\mathrm{N}^{\mathrm{o}} 2$.
\end{abstract}

En la nueva sala didáctica de nuestro museo se acaba de montar la exposición sobre la evolución de la cerámica típica de esta región. ¡Y esto abarca ya ocho épocas distintas!:

1) Cerámica "primitiva" incipiente, generalmente con pasta compuesta por abundantes granitos de cuarzo.

2) Cerámica roja pulida, lisa y grabada.

3) Cerámica de transición con técnicas mezcladas roja y negra pulida.

4) Cerámica San Pedro negra pulida y lisa, con pastas impregnadas de polvo de manganeso, y la grabada compuesta especialmente por los elementos estilísticos que llamamos el "juego de cola".

Museo Arqueológico de San Pedro de Atacama, Universidad del Norte, CHILE.
5) Cerámica negra "casi pulida" lisa y grabada con formas, pastas y grabados totalmente distintos a los de la Fase IV.

6) Cerámica "concho de vino", con formas típicas de superficie roja-violácea predominantes.

7) Cerámica "incásica" local e intrusiva que acompaña a la Fase VI durante la segunda parte de su período.

8) Cerámica "colonial”-regional, con las típicas pastas llenas de polvo de mica dorada.

En este esquema hablamos únicamente de la alfarería atacameña, sin considerar sus relaciones con el desarrollo cerámico de las áreas vecinas o extranjeras, que aparecen aquí como intrusivas, sin influenciar los tipos atacameños. Incluso, ni la cerámica Tiahuanacoide logró influenciar a los tipos locales, como se ha pretendido decir en más de alguna oportunidad.

Debemos agregar, en consecuencia, que los tipos de la alfarería Negra Pulida, en la medida que avanzamos con nuestras investigaciones, son más variados, pues ha aumentado la cantidad de especímenes excavados. Para sorpresa de la autora, ahora contamos con 73 variedades, sin contar otros grupos separados por variedades de altura y diámetros. Esperamos que la Dra. Tarragó continúe con sus interesantes investigaciones que requieren de la revisión de estas nuevas evidencias. Así, por ejemplo, se deberá intensificar el método de seriación en los botellones con diseños estilizados en donde abundan los puntos o perforaciones (zona cuello-boca) con 4 o 5 depresiones. Los casos de 6 o 7 puntos no los recordamos como representativos en nuestras colecciones.

Con esto deseamos señalar a nuestros lectores que en nuestra región de estudio no se terminan las investigaciones, de modo que las conclusiones 
nunca serán definitivas. ¡Por el contrario! Tanto en el Neolítico como entre las piedras talladas del Paleolítico debemos estar aptos y listos para aceptar cambios y modificaciones a nuestras últimas ideas e hipótesis, adaptándonos científicamente a las nuevas evidencias de los más recientes hallazgos.

San Pedro de Atacama, octubre de 1975. 